УДК 339

\title{
СИСТЕМА ПУНКТОВ ПРОПУСКА ЧЕРЕЗ ГОСУДАРСТВЕННУЮ ГРАНИЦУ ХАБАРОВСКОГО КРАЯ: СОСТОЯНИЕ И ПЕРСПЕКТИВЫ РАЗВИТИЯ
}

\author{
Дьячкова Ангелина Александровна \\ студент \\ Научный руководитель: Меркулов Виктор Игоревич \\ старший преподаватель \\ ФГАОУ ВО «Санкт-Петербургский политехнический \\ университет Петра Великого»
}

\begin{abstract}
Аннотация: Развитие внешнеэкономических взаимосвязей предъявляет высокие требования к трансграничной инфраструктуре, в том числе созданию достаточно развитой системы пунктов пропуска через государственную границу РФ. В статье представлена оценка системы пунктов пропуска в разрезе субъектов Дальневосточного федерального округа, рассмотрены состояние и характеристики пропускных пунктов на территории Хабаровского края, обозначены основные проблемы их функционирования, определены возможные пути развития пунктов пропуска через государственную границу.
\end{abstract}

Ключевые слова: внешнеэкономическая деятельность, пункт пропуска, трансграничная инфраструктура, приграничный регион, Хабаровский край

\section{THE SYSTEM OF CHECKPOINTS ACROSS THE STATE BORDER OF THE KHABAROVSK TERRITORY: THE STATE AND DEVELOPMENT PROSPECTS}

\section{Angelina Alexandrovna Dyachkova Merkulov Viktor Igorevich}

\begin{abstract}
The development of foreign economic relations places high demands on cross-border infrastructure, including the creation of a sufficiently developed system of checkpoints across the state border of the Russian Federation. The article presents an assessment of the system of checkpoints in the context of the subjects of the Far Eastern Federal District, examines the condition and characteristics of checkpoints on the territory of the Khabarovsk Territory, identifies the main


problems of their functioning, identifies possible ways of developing checkpoints across the state border.

Key words: foreign economic activity, checkpoint, cross-border infrastructure, border region, Khabarovsk Territory

Эффективность внешнеэкономической деятельности субъекта Российской Федерации и страны в целом зависит от множества факторов, значимыми из которых являются уровень развития системы пропускных пунктов через государственную границу и наличия развитой транспортной инфраструктуры в приграничных регионах.

Научные труды отечественных авторов в основном посвящены технологическим аспектам деятельности пунктов пропуска через государственную границу. Вопросам таможенного контроля посвящены труды В.А. Останина, П.В. Довженко, А.В. Борисенко, Р.А. Фанина, М.В. Шестернина, Е.Г. Бормотовой, Н.Г. Липатовой, Д.Б. Шипилова. Такие авторы, как В.И. Пилипчук, Н.К. Семенова, П.Ю. Королев, Е.И. Антонова, Т.И. Белоусова рассматривают в своих трудах общие вопросы функционирования пунктов пропуска. Аспекты региональных особенностей функционирования пунктов пропуска через государственную границу рассмотрены в трудах О. С. Цветковой, И.Э. Хрущева, П.П. Володькина, В.А. Лазарева, К.В. Калещук, А.Б. Бардаль, М.А. Сигитовой.

Отсутствие в настоящее время для характеристики инфраструктуры пунктов пропуска общепринятых показателей, дает возможность использовать любые элементы. В своих трудах А. Б. Бардаль предлагает для характеристики инфраструктуры пересечения государственной границы использовать относительную плотность пунктов пропуска [1, с. 15].

Опираясь на рекомендации данного автора, используем для характеристики инфраструктуры пересечения государственной границы количество пунктов пропуска и их плотность относительно заселенности и масштабов экономической деятельности в разрезе субъекта Дальневосточного федерального округа (ДФО).

На сегодняшний день в ДФО обустроено 86 пунктов пропуска через государственную границу, 25 из которых не функционируют. Действующие пропускные пункты представлены разными видами по типу международного сообщения, из которых 12 - автомобильные; 6 - смешанные; 11 - воздушные; 27 - морские; 6 - железнодорожные; 1 - речной (табл. 1) [2]. 
Таблица 1

Количество пунктов пропуска через государственную границу

в Дальневосточном федеральном округе

\begin{tabular}{|c|c|c|c|c|c|c|c|c|}
\hline \multirow[b]{2}{*}{ Субъект ДФО } & \multicolumn{8}{|c|}{ Количество пунктов пропуска через государственную границу } \\
\hline & всего & $\begin{array}{l}\text { автомо- } \\
\text { бильный }\end{array}$ & $\begin{array}{l}\text { смешан- } \\
\text { ный }\end{array}$ & $\begin{array}{l}\text { воздуш- } \\
\text { ный }\end{array}$ & $\begin{array}{l}\text { мор- } \\
\text { ской }\end{array}$ & $\begin{array}{c}\text { железно- } \\
\text { дорож- } \\
\text { ный }\end{array}$ & $\begin{array}{l}\text { реч- } \\
\text { ной }\end{array}$ & $\begin{array}{l}\text { пеше- } \\
\text { ходный }\end{array}$ \\
\hline Хабаровский край & $10 / 8$ & $1 / 0$ & $1 / 1$ & $1 / 1$ & $5 / 5$ & $1 / 0$ & $1 / 1$ & - \\
\hline Приморский край & $18 / 17$ & $5 / 4$ & - & $1 / 1$ & $9 / 9$ & $3 / 3$ & - & - \\
\hline Еврейская & $1 / 0$ & - & $1 / 0$ & & - & - & - & - \\
\hline Амурская область & $7 / 4$ & $1 / 1$ & $4 / 2$ & $1 / 1$ & - & - & - & $1 / 0$ \\
\hline Республика Бурятия & $10 / 4$ & $8 / 2$ & - & $1 / 1$ & - & $1 / 1$ & - & - \\
\hline Сахалинская & $13 / 9$ & - & - & $1 / 1$ & $12 / 8$ & - & - & - \\
\hline Камчатский край & $2 / 2$ & - & - & $1 / 1$ & $1 / 1$ & - & - & - \\
\hline Магаданская & $2 / 2$ & - & - & $1 / 1$ & $1 / 1$ & - & - & - \\
\hline Чукотский & $8 / 5$ & - & - & $2 / 2$ & $6 / 3$ & - & - & - \\
\hline Республика Саха & $3 / 2$ & - & $2 / 1$ & $1 / 1$ & - & - & - & - \\
\hline Забайкальский край & $12 / 8$ & $9 / 5$ & - & $1 / 1$ & - & $2 / 2$ & - & - \\
\hline ДФО всего & $86 / 61$ & $24 / 12$ & $10 / 6$ & $11 / 11$ & $34 / 27$ & $7 / 6$ & $1 / 1$ & $1 / 0$ \\
\hline
\end{tabular}

Расчет плотности относительно заселенности и экономической деятельности субъекта с учетом общего числа пропускных пунктов и действующих важен, так как значения показателей в отдельных субъектах значительно отличаются (табл. 2).

Таблица 2

Характеристики частей инфраструктуры международных взаимосвязей субъектов ДФО

\begin{tabular}{|c|c|c|c|c|c|}
\hline \multirow[b]{2}{*}{ Субъект ДФО| } & \multirow[b]{2}{*}{$\begin{array}{l}\text { Количе- } \\
\text { ство пунк- } \\
\text { тов про- } \\
\text { пуска }\end{array}$} & \multirow[b]{2}{*}{$\begin{array}{c}\text { Заселён- } \\
\text { ность, млн. } \\
\text { чел }\end{array}$} & & \multicolumn{2}{|c|}{ Плотность } \\
\hline & & & $\begin{array}{c}\text { Валовый ре- } \\
\text { гиональный } \\
\text { продукт,трл } \\
\text { н. руб. }\end{array}$ & $\begin{array}{c}\text { Относи- } \\
\text { тельно за- } \\
\text { селенности } \\
\text { (число } \\
\text { пунктов } \\
\text { пропуска } \\
\text { на } 1 \text { млн } \\
\text { чел. насе- } \\
\text { ления) }\end{array}$ & $\begin{array}{c}\text { Относительно } \\
\text { экономиче- } \\
\text { ской деятель- } \\
\text { ности субъ- } \\
\text { екта (число } \\
\text { пунктов про- } \\
\text { пуска на 1 } \\
\text { трлн руб. } \\
\text { ВРП) }\end{array}$ \\
\hline
\end{tabular}


Продолжение таблицы 2

\begin{tabular}{|c|c|c|c|c|c|}
\hline Хабаровский край & $10 / 8$ & 1,30 & 0,80 & $7,7 / 6,2$ & $12,5 / 10,0$ \\
\hline Приморский край & $18 / 17$ & 1,87 & 1,07 & $9,6 / 9,1$ & $16,9 / 15,9$ \\
\hline $\begin{array}{c}\text { Еврейская автономная } \\
\text { область }\end{array}$ & $1 / 0$ & 0,15 & 0,06 & $6,7 / 0$ & $17,7 / 0$ \\
\hline Амурская область & $7 / 4$ & 0,77 & 0,04 & $9,1 / 5,2$ & $169,7 / 97,0$ \\
\hline Республика Бурятия & $10 / 4$ & 0,98 & 0,29 & $10,2 / 4,1$ & $35,0 / 14,0$ \\
\hline Сахалинская область & $13 / 9$ & 0,48 & 1,17 & $27,1 / 18,8$ & $11,1 / 7,7$ \\
\hline Камчатский край & $2 / 2$ & 0,31 & 0,28 & $6,5 / 6,5$ & $7,2 / 7,2$ \\
\hline Магаданская область & $2 / 2$ & 0,14 & 0,21 & $14,3 / 14,3$ & $9,4 / 9,4$ \\
\hline $\begin{array}{c}\text { Чукотский автономный } \\
\text { округ }\end{array}$ & $8 / 5$ & 0,05 & 0,09 & $160 / 100$ & $84,3 / 52,7$ \\
\hline $\begin{array}{c}\text { Республика Саха } \\
\text { (Якутия) }\end{array}$ & $3 / 2$ & 0,99 & 1,22 & $3,0 / 2,0$ & $2,5 / 1,6$ \\
\hline Забайкальский край & $12 / 8$ & 1,04 & 0,36 & $11,5 / 7,7$ & $32,9 / 21,9$ \\
\hline ДФО всего & $86 / 61$ & 8,08 & 5,97 & $10,6 / 7,5$ & $14,4 / 10,2$ \\
\hline \multicolumn{6}{|c|}{$\begin{array}{c}\text { Примечание: в числителе представлены данные относительно общего количество пунктов } \\
\text { пропуска, в знаменателе - относительно функционирующих пунктов пропуска } \\
\text { в настоящее время }\end{array}$} \\
\hline
\end{tabular}

Значения показателей плотности относительно заселенности и ВРП свидетельствуют об опережении Хабаровского края перед другими субъектами ДФО (исключение ЕАО, Камчатский край и Республики Саха (Якутия) по заселенности и опережении относительно таких субъектов ДФО как Приморский край, ЕАО, Амурская область, Республика Бурятия, ЧАО, Забайкальский край по масштабам экономической деятельности.

Хабаровский край занимает выгодное географическое положение, на его территории проходит часть государственной границы России с КНР, что позволяет региону вести эффективную внешнеэкономическую деятельность. Развитие внешней торговли и туризма в Хабаровском крае предъявляет высокие требования к совершенствованию трансграничной инфраструктуры и созданию соответствующих современным условиям пунктов пропуска через государственную границу России.

По состоянию на 2022 год в Хабаровском крае установлено 10 пограничных пунктов, из них функционирует 8: 1 - воздушный; 5 - морских; 1 - речной; 1 - смешанный (табл. 3). 
Таблица 3

Характеристика действующих в Хабаровском крае пропускных пунктов через государственную границу

\begin{tabular}{|c|c|c|c|c|c|c|}
\hline $\begin{array}{c}\text { Наименова- } \\
\text { ние пропуск- } \\
\text { ного пункта }\end{array}$ & $\begin{array}{c}\text { Сопре- } \\
\text { дельный } \\
\text { пункт } \\
\text { пропуска }\end{array}$ & $\begin{array}{l}\text { Вид пропуск- } \\
\text { ного пункта }\end{array}$ & $\begin{array}{c}\text { Статус пункта } \\
\text { пропуска }\end{array}$ & $\begin{array}{c}\text { Характер меж- } \\
\text { дународного } \\
\text { сообщения }\end{array}$ & $\begin{array}{l}\text { Режим ра- } \\
\text { боты }\end{array}$ & $\begin{array}{l}\text { Время } \\
\text { работы }\end{array}$ \\
\hline Хабаровск & $\begin{array}{l}\text { Фуюань } \\
\text { (Китай) }\end{array}$ & речной & многосторонний & $\begin{array}{c}\text { грузо- } \\
\text { пассажирский }\end{array}$ & $\begin{array}{c}\text { постоян- } \\
\text { ный }\end{array}$ & ежедневно \\
\hline $\begin{array}{c}\text { Хабаровск } \\
\text { (новый) }\end{array}$ & - & воздушный & многосторонний & $\begin{array}{c}\text { грузо- } \\
\text { пассажирский }\end{array}$ & $\begin{array}{c}\text { постоян- } \\
\text { ный }\end{array}$ & $\begin{array}{c}\text { круглосу- } \\
\text { точно }\end{array}$ \\
\hline Ванино & - & морской & многосторонний & грузовой & $\begin{array}{c}\text { постоян- } \\
\text { ный }\end{array}$ & $\begin{array}{l}\text { круглосу- } \\
\text { точно }\end{array}$ \\
\hline $\begin{array}{l}\text { Николаевск- } \\
\text { на-Амуре }\end{array}$ & - & морской & многосторонний & $\begin{array}{c}\text { грузо- } \\
\text { пассажирский }\end{array}$ & сезонный & $\begin{array}{c}\text { ежедневно в } \\
\text { навигацион- } \\
\text { ный период }\end{array}$ \\
\hline Охотск & - & морской & многосторонний & грузовой & $\begin{array}{c}\text { постоян- } \\
\text { ный }\end{array}$ & ежедневно \\
\hline Де-Кастри & - & морской & многосторонний & грузовой & $\begin{array}{c}\text { постоян- } \\
\text { ный }\end{array}$ & $\begin{array}{c}\text { круглосу- } \\
\text { точно }\end{array}$ \\
\hline $\begin{array}{c}\text { Советская } \\
\text { Гавань }\end{array}$ & - & морской & многосторонний & $\begin{array}{c}\text { грузо- } \\
\text { пассажирский }\end{array}$ & $\begin{array}{c}\text { постоян- } \\
\text { ный }\end{array}$ & $\begin{array}{c}\text { ежедневно } \\
\text { кроме вос- } \\
\text { кресенья и } \\
\text { государ- } \\
\text { ственных } \\
\text { праздников }\end{array}$ \\
\hline Покровка & $\begin{array}{l}\text { Жахоэ } \\
\text { (Китай) }\end{array}$ & смешанный & двусторонний & $\begin{array}{c}\text { грузо- } \\
\text { пассажирский }\end{array}$ & $\begin{array}{c}\text { постоян- } \\
\text { ный }\end{array}$ & ежедневно \\
\hline
\end{tabular}


Автомобильный пропускной пункт «Большой Уссурийский» сопредельный с пропускным пунктом Хэйсяцзыдао (Китай) в настоящее время не действует в связи с отсутствием пассажиропотока в данном направлении.

От регламента работы пропускного пункта во многом зависит его время прохождения контрольных процедур при пересечении границы, сроки доставки грузов. Четыре пропускных пункта Хабаровского края работают в круглосуточном режиме, тем самым обеспечивая беспрерывное перемещение грузов и пассажиров.

В настоящее время основными странами-контрагентами Хабаровского края являются Китай, Казахстан, Республика Корея, Япония, Филиппины. На данные страны приходится наибольший объем внешнеторгового оборота Хабаровского края. Суммарный внешнеторговый оборот Хабаровского края в 2020 году составил 2586,1 млн. долларов США, что на 132,8 млн. долларов США меньше, чем в 2019 году или на 4,9 \% (таб. 4) [3].

Таблица 4

Показатели внешней торговли Хабаровского края за 2018-2020 года

\begin{tabular}{|c|c|c|c|}
\hline Показатель & 2018 год & 2019 год & 2020 год \\
\hline Внешнеторговый оборот млн. дол. США & 3108,3 & 2718,9 & 2586,1 \\
\hline Экспорт, млн. дол. США & 2573,4 & 1847,1 & 1806,3 \\
\hline Импорт, млн. долл. США & 534,9 & 871,8 & 779,9 \\
\hline
\end{tabular}

Основную долю во внешнеторговом обороте Хабаровского края занимает экспорт (69,8 \%), направленный в страны Азиатско-Тихоокеанского региона (АТР). В 2020 году экспорт Хабаровского края составил 1806,3 млн. долл. США, что на 40,7 млн. долл. США меньше данного показателя 2020 года. Основной странами в экспорте является Китай (38,7 \% экспорта) и Республика Корея (21 \% экспорта) [4]. Динамика показателей внешней торговли Хабаровского края с сановными странами-контрагентами представлена на рисунке 1. 


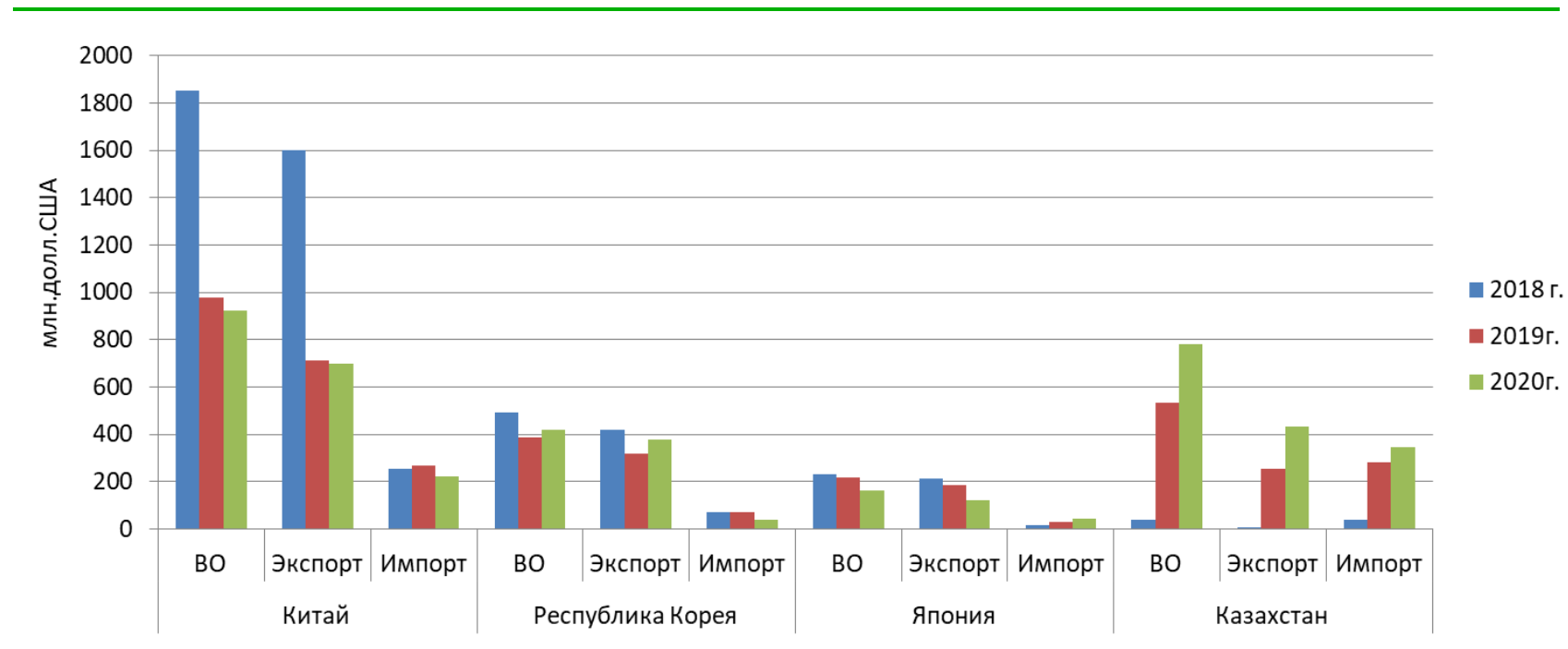

Рис. 1. Динамика показателей внешней торговли Хабаровского края с основными странами-контрагентами

Наращивание экспорта Хабаровского края приходится на такие виды товаров, как продукиия рыбопромышленного комплекса, жемчуг природный и драгоценные металлы. Для региона рост эскорта - это поступление валютной выручки, заключение новых внешнеэкономических контрактов. Динамика пяти ведущих товаров экспорта представлена на рисунке 2.

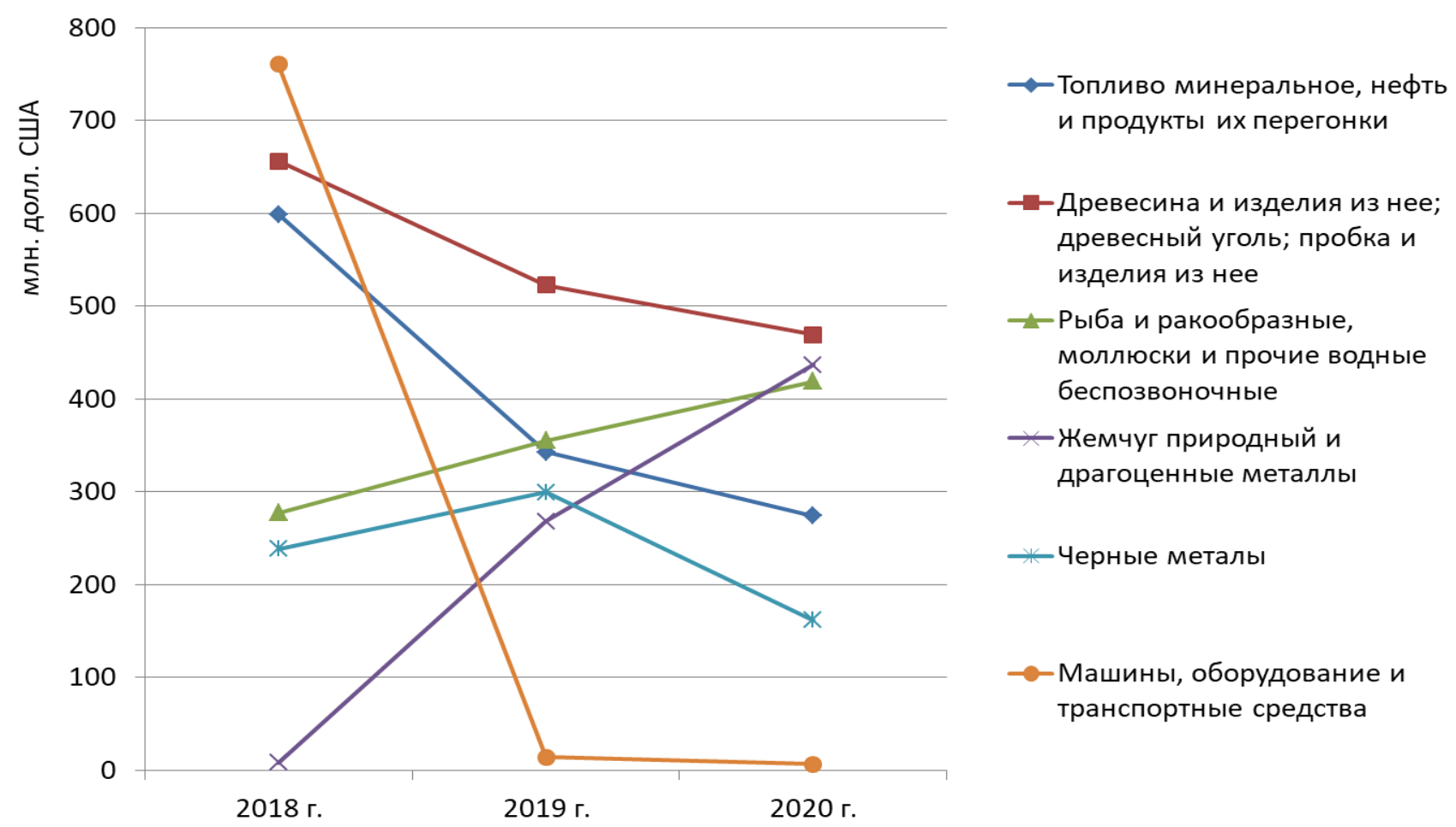

Рис. 2. Динамика пяти ведущих товаров экспорта 
Увеличение импорта Хабаровского края в 2020 году происходит по таким видам товаров как минеральные продукты, включая рудные концентраты (доля в импорте 46,2\%), и продукция машиностроения. Доля минеральных продуктов в общей стоимости импорта составила, продукции машиностроения (доля в импорте $27,0 \%$ ). Динамика пяти ведущих товаров импорта представлена на рисунке 3.

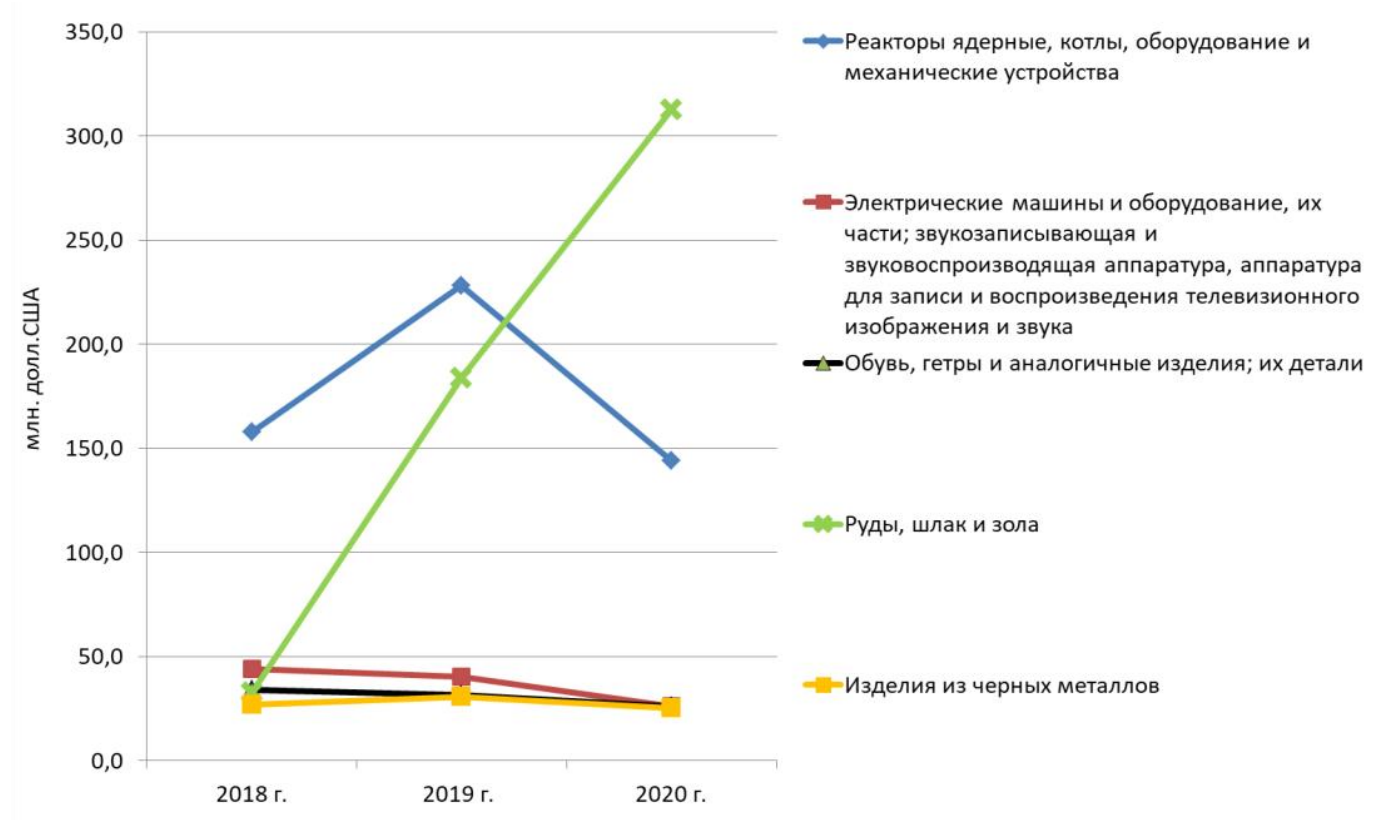

Рис. 3. Динамика пяти ведущих товаров импорта

В экспорте и импорте услуг основными являются транспортные услуги $95,7 \%$ и $72,4 \%$ соответственно.

Расширение взаимодействий Хабаровского края с зарубежными странами требует наличия достаточно развитых по масштабу и качеству транспортной, таможенной, пограничной инфраструктур, которые позволяют обеспечить безопасность государственной границы, способствовать развитию международных транспортных коридоров и развитию транзитного потенциала региона и страны в целом.

В настоящее время в Хабаровском крае проблемой пропускных пунктов через государственную границу является высокая степень износа инфраструктуры. По данным Росгранстрой в Хабаровском крае только аэропорт Хабаровск (Новый) соответствует всем нормативным требованиям. В связи с этим осуществляется модернизация и развитие пунктов пропуска через государственную границу в регионе. В рамках национального проекта 
«Международная кооперация и экспорт» осуществляется обустройство и реконструкция морского пункта пропуска «Ванино».

Для дальнейшего наращивания внешнеэкономической активности в Хабаровском крае необходимо произвести техническое переоснащение инфраструктуры речного пункта пропуска «Хабаровск», а именно: привести модернизацию инфраструктуры пункта пропуска через государственную границу пассажирского направления; обновить грузовой и пассажирский флот, который будет соответствовать современным требованиям и условиям для работы на международных линиях. Данные мероприятия позволят расширить внешнеэкономическое взаимодействие с провинцией Фуюань (Китай).

Также необходимо совершенствовать единственный смешанный пропускной пункт «Покровка», расположенный в селе Покровка Бикинского района Хабаровского края на берегу реки Уссури. Пограничный переход между Покровкой и уездом Жаохэ китайской провинции Хэйлунцзян КНР единственный круглогодичный речной переход, соединяющий провинцию и Хабаровский край зимой и летом. Летом работает речная переправа и перевозки грузов и пассажиров осуществляются речным транспортом, зимой функционирует понтонный мост и перевозки осуществляются автомобильным транспортом. Реконструкция в пункте пропуска не проводилась. Одним из путей повышения эффективности работы пропускного пункта «Покровка» является строительство моста между пунктами пропуска Покровка и Жаохэ (Китай) через реку Уссури, а также модернизация инфраструктуры с российской стороны.

Развитие и переоснащение инфраструктуры пунктов пропуска через государственную границу в Хабаровском крае поможет решить проблему скопления транспорта на границе, сократится время при пересечении границы и время доставки грузов, поспособствует улучшению условий труда сотрудников и условий пребывания лиц, пересекающих государственную границу, в пунктах пропуска.

Таким образом, оптимизация работы пунктов пропуска через государственную границу в Хабаровском крае, в том числе реконструкция имеющихся и строительство новых объектов в пунктах пропуска, а также совершенствование функционирования пропускных пунктов за счет технического переоснащения и внедрения новых автоматизированных систем, позволит эффективно развивать внешнеэкономические связи, увеличивая грузовые и пассажирские потоки. 


\section{Список литературы}

1. Бардаль А.Б. Система пунктов пропуска через государственную границу: российский Дальний Восток // Власть и управление на Востоке России. - 2018. - № 1 (82). - С. 14-22.

2. Росгранстрой. Пункты пропуска : сайт. - URL : https://rosgranstroy.ru/ checkpoints/the-list-of-checkpoints/ (дата обращения 20.01.2022).

3. Дальневосточное таможенное управление : сайт. - URL : https://dvtu. customs.gov.ru/folder/230482 (дата обращения 29.01.2022).

4. Внешняя торговля Хабаровского края по итогам 2020 года : сайт. URL: https://minec.khabkrai.ru/?menu=getfile\&id=12210 (дата обращения 30.01.2022).

5. Хрущев И.Э. Мероприятия по строительству и модернизации пунктов пропуска на Дальнем Востоке // Таможенная политика России на Дальнем Востоке. - 2020. - № 4 (93). - С. 43-46.

(C) А.А. Дьячкова, 2022 